\title{
(Los poetas de farsantes»: Quevedo, Mateo Luján de Sayavedra y la caricatura del mal dramaturgo a comienzos del XVII
}

\author{
Héctor Brioso Santos \\ Departamento de Filología, Comunicación y Documentación \\ Universidad de Alcalá \\ Colegio San José de Caracciolos \\ C / Trinidad, 3 \\ 28801 Alcalá de Henares \\ hbrioso@hotmail.com \\ [La Perinola, (IssN: 1138-6363), 22, 2018, pp. 39-64] \\ DOI: $10.15581 / 017.22 .39-64$
}

La sátira del mal poeta es un tópico de muy vieja data ${ }^{1}$ y el dramaturgo era, antes que nada, un poeta, como ya lo indicaba la polisemia de esa palabra en el Siglo de Oro: 'autor de poesía' y 'escritor de comedias"2. España hervía de dramaturgos mediocres desde finales del XVI, pues, según afirmaba Pierio en la cuarta de las Tablas poéticas de Francisco de Cascales, el género estaba de moda, era accesible y también -inferimos- rendía beneficios: “A lo que yo imagino, ancho campo tenéis donde correr agora en la comedia, que es lo más praticable que tenemos de la poesía y adonde más ejercitados están los poetas españoles»3.

De ahí que, dentro del general ataque a los vates adocenados, varias novelas ensayaran desde comienzos del XvII algunas sátiras contra los comediógrafos de poco fuste y sus comedias, a menudo impracticables para las compañías. En bastantes relatos comparecieron éstos, afanosos de vender su mercancía, armados con muestrarios de títulos y versos teatrales. Porque de la descripción de una mala comedia se pasó fácilmente al catálogo de piezas infames -en particular en el entremés $E l$ casamentero de Alonso de Castillo Solórzano (1627) - y finalmente a la representación efectiva de dos de ellas en un entremés y una mojiganga firmados por Pedro Calderón de la Barca, según detallé en otros dos trabajos sobre este mismo asunto (Brioso, 2015 y 2016).

1. Véanse los estudios de Sobejano, 1973, y Herrero, 1977.

2. Una ambigüedad resuelta por Quevedo en El alguacil endemoniado (Sueños, p. 149).

3. «In specie», IV, «De la comedia» (p. 203). 
El Guzmán de alfarache apócrifo, firmado por «Mateo Luján de Sayavedra, natural vecino de Sevilla» (Valencia, Pedro Patricio Mey, $1602)^{4}$, ofreció el primer ejemplo de un episodio teatral dentro de una novela, con la conversión del pícaro protagonista en actor $\mathrm{y}$, a modo de remate, la entrada en acción de un dramaturgo caricaturesco con su comedia bajo el brazo. Y Luján lo hizo de un modo ya completo y maduro, con bastantes de los ingredientes que ese tipo satírico en ciernes presentaría en obras posteriores. En estas páginas repasaré el pasaje en contraste con la imitación posterior de Quevedo y con algunos otros textos de esos años, aunque, por ahora, no puedan identificarse las posibles fuentes de inspiración del pseudo-Alemán.

Es el falso Guzmán un libro “curioso y con elegante estilo compuesto ${ }^{5}$, que su autor describió, sin embargo, en su dedicatoria, como una obra de título «de sí tan humilde» (p. 108), quizás por la inspiración ajena, o por ser obra de entretenimiento, apenas precedida en su especie narrativa por Lazarillo de Tormes y por la monumental novela de Mateo Alemán (1599). También es la Segunda parte apócrifa una obra contradictoria: si, por un lado, su oportunista autor manejó con cierta soltura una amena trama picaresca, por otro fue capaz de colarnos gato por liebre y llenar la novela de páginas hurtadas, en un plagio múltiple: por una parte, del personaje, la estructura, el punto de vista, el argumento y el planteamiento original bifronte de Alemán -los consejos y las consejas - y, por otra, del variopinto corpus de obras saqueadas, especialmente en su segunda mitad, donde se aleja de su modelo directo y se apoya aun más en los pasajes prestados ${ }^{6}$ Y es lo peor que con esa labor de taracea fue capaz de echar por tierra casi toda la eficacia moral que podía presumirse de una novela inspirada en el Guzmán original, aunque también ganó, a ratos, agilidad y amenidad narrativa.

$\mathrm{Y}$ es que tenemos en todo momento la sensación de estar ante un novelista no del todo inhábil, pero que, apegado a su modelo, se cree en la necesidad de entretejer las famosas admoniciones morales de éste, echando mano de materiales de acarreo. En ese terreno, la inferioridad del plagiario es evidente desde el comienzo, puesto que, frente a la

4. Lógicamente, no cumple tratar aquí cuestiones como las fuentes de los plagios internos o la atribución del falso Guzmán de Alfarache a Juan Martí, o últimamente al impresor y profesor levantino Juan Felipe Mey, exploradas ya por especialistas como Alan Francis, Donald McGrady, David Mañero o Marcial Rubio Arquez, entre otros. Al aludir indistintamente a Martí de Sayavedra, Luján o Mey me refiero al, por ahora, desconocido autor de la Segunda parte de 1602, sin más cábalas.

5. Según la aprobación de Pedro Joan Asensio, fechada el 8 de agosto de 1602 (Segunda parte, p. 105).

6. Me atengo al análisis del citado Mañero en su introducción (2007, pp. 37-40) y, en particular a la p. 38, donde anota: «A partir de este momento [libro II, cap. v], el apócrifo recurrirá aun con más frecuencia a otros autores para la inserción de pasajes digresivos». Por otro lado, se trata de un cambio de tercio anticipado por la aparición del archibribón Micer Morcón (desde la p. 290), un personaje extrapolado del Guzmán original (concretamente, de I, III, 3; p. 394). 
artillería prologal de su modelo sevillano, el Guzmán falso no ostenta más que una dedicatoria de compromiso. En cierto modo, se trata de un moralismo tan endeble y sobrevenido como el del Buscón, aunque el pseudo-alemán lo logre a base de plagios y Quevedo por medio de alguna sentencia ocasional poco convincente, como el famoso aforismo senequista del desenlace? ${ }^{7}$ Ya lo vio así Lázaro Carreter: «Mientras Alemán profundiza en el problema, lo desarrolla y lo muestra a varias luces, nuestro escritor [Quevedo] se limita a banalizarlo, a convertirlo en situación y caricatura» (1993, p. XVIII). Y algo similar cabe afirmar del valenciano, que construye su novela sobre una eficaz anécdota, pero nos cuela máximas, historietas y discursos ajenos en un verdadero collage narrativo. El resultado es también parejo: si Quevedo esquivaba, según Lázaro, cualquier escollo social o dogmático: «en no extralimitarse le iba la vida al artista» (1993, p. xvıı); "nada se roza ni se alude»; la materia se trabaja "sólo como fenómeno plástico» (p. XIX); “una situación profunda, un problema, se trivializa y se resuelve en pretexto para que el autor devane su prodigiosa madeja verbal»; “Quevedo ni moraliza ni protesta» (p. xx); «El Buscón se muestra, así, charla sin objeto, dardo sin meta, fantasmagoría» (p. xxI), etc., el falsificador, harto más limitado, ni siquiera debió plantearse ese riesgo, atribulado como estaba por cierta fragilidad moral y, en el fondo, expositiva o estructural.

Importa traer a colación en este punto el debate de la crítica neoguzmanista reciente: un sector postula que las digresiones ajenas de MartíLuján no son el síntoma de una impotencia creativa, sino, en realidad, una manifestación de hábil imitatio o incluso una reinterpretación o reescritura de libros de $\operatorname{moda}^{8}$. Y, en verdad, el problema es acuciante en nuestra época, un tiempo de revisionismos y de rescate de autores marginales: ¿Luján oportunista y tramposo, plagiario por partida doble, o Luján gran lector, antólogo del pensamiento de su tiempo y coleccionista de citas valiosas, que brinda generosamente a sus lectores?

Sea como fuere, lo que no cabe es pensar que con esos mimbres podía armarse una novela articulada ideológicamente, por más que las lecturas de su autor tuviesen un tono común o incluso reflejasen varias vertientes de un mismo tema ${ }^{9}$. Y el contraste con sus colegas, Alemán y Quevedo, en extremos opuestos, lo deja todavía más en evidencia: el primero construye una obra de formidable y granítica unidad ideológica; el segundo un juego satírico en el que lo ajeno, que es mucho ${ }^{10}$,

7. Véanse en especial esa sentencia final clásica de esa novela (p. 226) y la copiosa bibliografía aducida por Cabo en el prólogo (pp. 22-29) y al pie de su edición del Buscón (n. 226.86).

8. Mañero, 2007, p. 22, quien, a su vez, resume ideas de Francis, Labourdique, Cavillac y Rubio Arquez.

9. Mañero, 2007, p. 23.

10. A la zaga de las consideraciones de Lázaro Carreter, Chevalier anotó acertadamente: «Es innegable que Francisco de Quevedo aprovechó, lo mismo que Góngora, una nutrida serie de juegos de palabras y chistes familiares que formaban el núcleo de otras tantas historias extensamente difundidas [...]. El chiste quevedesco evocaría en la 
se tiñe de la peculiar tonalidad humorística del Quevedo joven y resulta, por tanto, «inconfundible, extraño, originalísimo», según Lázaro Carreter (1993, p. xx). Chevalier también habló de la «radical originalidad» y tono homogéneo del libro del Buscavidas (1992, p. 193). Muy otra cosa vino a afirmar Rico:

Quevedo entró a saco en el repertorio de elementos constitutivos del género, dispuesto a competir con el anónimo quinientista y con el sombrío Alemán, para vencerlos a punta de ingenio. Pero la suya era una inteligencia crítica y analítica [...], dada a desperdigarse en el detalle más que a demorarse en el enfrentamiento global de temas y problemas» (1973, p. 121).

Y, finalmente, para resumir el eterno debate crítico, Tobar Quintanar considera el Buscón una parodia del Guzmán de Alfarache (2011, p. 473, n. 68).

No logra tanto el escurridizo valenciano, un escritor relativamente capaz, pero pálido, sin criterio propio y tan acomodaticio que incluso se deja arrastrar por el torrente de las citas ajenas ${ }^{11}$. Carecía de espíritu crítico como para parodiar a su modelo y seguramente sólo deseaba escamotearle parte de sus jugosas ventas, y de ahí la improvisación. Su caso es casi indefendible. Para resumir una vasta bibliografía, Sobejano lo acusó de varios vicios novelescos, aludiendo incluso al asunto que nos ocupa:

No podemos en modo alguno suponer que todo cuanto en Luján se refiere al proyecto de viaje a Valencia reconozca como precedente los papeles y pensamientos de Alemán. En efecto, tras la salida de Alcalá, mediada ya la obra, Luján se diría que no sabe hacia dónde tirar y, para prolongar el relato, recurre a las soporíferas disertaciones del mozo vizcaíno, o se entretiene en preparar aquel imbécil turismo regio, haciendo que Guzmán pase precipitadamente de paje a galanteador de meretrices, de aquí a un grotesco noviciado, y que del claustro salte a la farándula y de la farándula a los celos, al robo de capas, al presidio y, en fin, a las galeras. Por el contrario, sus experiencias en Nápoles y camino de Alcalá, algún precedente habrán de tener en los papeles y pensamientos de Mateo Alemán, pues de no ser así habríamos de concluir que Luján no había plagiado más que el tipo del protagonista y su ruta de retorno $(1959, \text { s. p. })^{12}$.

mente del lector contemporáneo el recuerdo del aludido cuentecillo, que se dibujaba más o menos concretamente, como en filigrana, en la prosa o en los versos del escritor» («Cuentecillos y chistes...», p. 2).

11. Comp. Mañero, 2007, p. 24: «El interés por acercar al lector una amplia información de primera mano, por lo demás sin apenas alteración de las fuentes empleadas, llegará incluso a imponerse sobre el punto de vista del narrador implícito».

12. Y más abajo añade: “Uno de los errores más torpes del continuador apócrifo consiste justamente en haber dado entrada excesiva en su obra a estas enseñanzas, que en él adquieren a veces un aire de pedantería banal»; “Concluyamos que si Luján mantuvo el nivel lazarillesco-picaresco del primer Guzmán, sus sátiras, moralidades y enseñanzas, algunas arrancadas a Ravisio Textor, al Padre Cabrera o al interesante asceta seglar Alejo Venegas, degeneraron en la más soporosa ramplonería»; “Las digresiones de Luján, el imitador, [...] nos fastidian: están puestas sin gracia y expuestas sin galanura». 
Con todo, percibimos que el plagiario imita, a su modo un tanto superficial, las moralidades de su maestro, urdiendo discursos a ratos convincentes y que alguna vez pueden incluso parecer pseudo-alemanianos, aunque no alcancen nunca la seca coherencia y la expresividad de su maestro $^{13}$. Pensemos que, frente a la fuerza del sevillano, el valenciano resulta más endeble $\mathrm{o}$, como ha afirmado Mañero:

Las digresiones de Alemán, definidas por un planteamiento cerrado y monocorde, dan paso en la obra de 'Luján' a una yuxtaposición de períodos digresivos en los que vemos expuestas de manera independiente las distintas posturas enfrentadas, en ocasiones sin que llegue a ofrecerse una conclusión alegórica (2007, p. 23).

Ello no impide al imitador - recalco-, ser un lector pasable de Alemán y de la incipiente picaresca, como demuestra con buenos argumentos ese mismo crítico (2007, pp. 28-30).

La inconsistencia del levantino lo es, sobre todo, en contraste con el vigor de su modelo, y reprocharle ese defecto equivaldría, en definitiva, a descartar literariamente muchas novelas picarescas epigonales en virtud de su moralismo superficial, sin atender a la invención, el estilo, la agilidad narrativa y el interés de los personajes o las situaciones. Ese género multiforme viró casi desde sus inicios, después del Guzmán hispalense, de la interioridad original hacia una exterioridad un tanto banal y una aparatosa exhibición de ingenio, que a menudo degenera en galería de chistes o en sarta heteróclita de elementos ${ }^{14}$. Del mismo modo que Alemán no sentó cátedra, casi todos sus oportunistas discípulos sólo lo fueron en la forma, en la hechura exterior y no en el fondo socio-moral, Luján y Quevedo los primeros ${ }^{15}$. Quizás por ello, mientras la novela del sevillano no es plato de gusto del lector moderno a causa de su sermoneo, bastantes obras de sus seguidores pueden leerse hoy con agrado.

Vayamos a nuestros elementos de juicio, puros y duros. El episodio metaliterario que nos importa ahora ocupa los capítulos vII a XI del libro III de la Segunda parte, casi un centenar de páginas en la edición moderna, acaso inspiradas por el ambiente de tertulias, academias y desvanes de corrales hacia 1600. Sin que podamos precisar exactamente de dónde lo extrajo, aparece ahí por vez primera en la novela del xvII nuestro motivo satírico-teatral, puesto que Alemán lo había esquivado

13. Así, por ejemplo, en Segunda parte, libro I, cap. v, p. 195, sobre el vestido; pp. 198199, acerca de las relaciones entre las mujeres, el dinero y la concupiscencia. A renglón seguido, incluso imita la conciencia guzmaniana (p. 199) y, poco después, remeda la voz de su inspirador sevillano: «no te maravilles amigo, que haga algunos discursillos y te dé cuenta de mis pensamientos»; “mi digresión» (p. 200); “tú que escuchas mi vida» (p. 208), etc.

14. La bibliografía sobre esta deriva aguda es profusa: baste con repasar el capítulo xv del libro clásico de Chevalier, 1992.

15. El citado Chevalier, 1992, p. 192, dio en el clavo: «Me pregunto si la genealogía del antihonor tiene sentido en la 'novela picaresca' fuera del Lazarillo y de Guzmán. ¿No vendrá a ser, con La pícara Justina y El Buscón, mero pretexto a juegos de palabras?». 
en 1599 y dado que no volveremos a encontrarlo hasta el Buscón, que suele datarse ahora algo después de la fecha tradicional de 1604 o $1605^{16}$. La pícara Justina será un caso distinto en 1605 porque el componente teatral resulta en ella mucho más anecdótico y pasajero.

Los citados Rico y Lázaro Carreter percibieron claramente la inspiración de Quevedo en las páginas del falsario; el segundo sentenció: «La influencia argumental que considero más transparente en nuestro libro es la del falso Guzmáns ${ }^{17}$; y más abajo ejemplificó los paralelos:

Hallamos en la continuación de Sayavedra a un galán de monjas. Y también la conversión del pícaro en actor, por amor de una cómica [...]. Guzmán y Pablos, que empiezan su carrera con papeles de poca monta, muestran en seguida gran aptitud como representantes y escalan los primeros puestos de la compañía. [...] Sayavedra describe la hilarante lectura de la comedia con rasgos que recuerdan el episodio de El Arca de Noé, la pieza de animales que un poeta recita a Pablos camino de Madrid (1993, pp. XVI-XVII).

Para recapitular finalmente: «Estas concomitancias [...] ofrecen al crítico lo que más puede desear: bases de comparación» (p. XviI).

Repasemos los pasajes del apócrifo desde que la fiebre libresca, dramática y amorosa se apodera del protagonista:

Dígote, pues, que me amanecían los libros en la mano y me acostaba con ellos, y en esto notarás cómo obraron en mí sus fieros hechizos, que con el gusto de los versos y el de ver recitalles en las farsas, a que era muy aficionado, me puse en la cabeza de ser representante; para esto di en frecuentar más el corral de la Cruz, donde representaba Heredia. Parecíame bien la vida libertada y vagabunda desta manera de gente, que hoy están en la Corte, mañana en Sevilla y esotro en Toledo, y gozan cada día de ver mundo nuevo, buenos trajes, y se gasta sin pensar en el de mañana. Este exterior me satisfacía mucho, aunque después vi cuán amargo es lo que fuera parece deleitoso.

Empecé a tomar amigos de la compañía y quedarme a ver ensayar, y aun me ensayé a decir amores y solicitallos a una buena oficiala de todo. Como no le vinieron de nuevo, no me desdeñó de manera que tuviese yo de qué desesperar, sino que me trató al principio como a boquirrubio, hasta que

16. El Buscón pudo redactarse en fechas algo posteriores a la aparición del falso Guzmán. El joven Quevedo había compuesto ya en los albores de su carrera, entre 1600 y 1605, varias obras paródicas y burlescas, en las que los poetastros aparecen varias veces: Premática de 1600, Premáticas destos reinos, Premática de aranceles generales, Premática del tiempo, Premáticas del desengaño contra los poetas güeros, Capitulaciones matrimoniales, Memorial que dio en una academia, Carta a la rectora del colegio de las vírgenes, Vida de corte y ocios entretenidos en ella y Origen y difinición de la necedad, además de un puñado de poemas más o menos ligeros y burlescos. Cabo, 1993, p. 15, anotó para el Buscón el posible lapso 1606-1613 y Tobar, 2011, pp. 468-474, ha conjeturado que tuvo que escribirse entre la aparición del primer Quijote en 1605 y abril de 1608.

17. Lázaro Carreter, 1993, pp. xvi-Xvir. Comp. Rico, 1973, p. 236, quien aclaró que el Buscón pudo seguir las aventuras de los dos Guzmanes con el fin de que su novela fuera reconocida por los lectores como un relato picaresco al uso. 
entendió de mí que de puro rubio era ya blanco como el vino añejo, y que tenía más de rancio que de verde; pero después sabrás el suceso (Segunda parte, pp. 519-520).

Sale a relucir ya aquí el motivo de la amante actriz, que después dará lugar a nuevos episodios y que será imitado por Quevedo. Sigue una viñeta casi costumbrista sobre la recepción del teatro:

Una tarde, con dos camaradas mías de buen gusto me iba a ver la farsa; leímos los carteles en una esquina: vimos que en el de la Cruz se representaba la Ifigenia, tragedia, y en el del Príncipe una comedia. Había quien quería ver comedia y no tragedia, porque era muy compasivo y llorón; resolvióse de conformidad que fuésemos a lo más cerca.

Llegábamos a esta razón al monasterio de la Santísima Trinidad, porque habíamos bajado de la calle de las Urosas y subido la de Relatores, y así como a más cerca nos fuimos al de la Cruz a ver la tragedia. Y tanto me enfadé del mal fin y suceso della, que por poco estuve de no tratar de ser farsante, pero la añagaza de mis nuevos amores me volvían con más violencia que con un trabuco.

Poco reparaba yo en la vileza de la profesión, que aun desto no tuve primer movimiento. No consideraba que, aunque la poesía es arte noble, principal y liberal, pero que la acción della en el teatro está muy abatida, de tal manera, que hay muchos que no solamente tienen a los que ejercitan esto por infames, pero imaginan que no se les debe dar el Santísimo Sacramento [...]. Es la verdad que cierta manera de representantes son viles y bajos y muy infames; es, a saber: los que, como agora los zarabandistas con movimientos torpes y deshonestos incitaban e incitan a torpeza y deshonestidad (Segunda parte, pp. 520-521) ${ }^{18}$.

Pero baste con lo citado, pues, según han demostrado las investigaciones sobre las fuentes del libro desde McGrady, lo que sigue no es sino una taracea de frases hurtadas de López Pinciano ${ }^{19}$.

Con todo, quizás acicateado por la verborrea alemaniana, por la lectura del Pinciano o por el simple afán de llenar páginas, nuestro oportunista autor de 1602 llega a añadir algunas reflexiones teatrales que, por el momento, parecen ser de su cosecha:

Muy poco reparaba yo en el provecho universal ni particular; que, quien de sí mismo disponía tan mal, cierto es que no miraría por el bien común; pero hete dicho lo que hay en la práctica de la representación, si se usase con el modo debido, que en el modo y la materia está el bien o mal, que, aunque a veces por ir a caza de cosas graciosas se mezclan palabras y refieren cosas que tienen alguna oscuridad, pero esto no quita el pasto y materia de toda la farsa, que siendo buena y de enseñanza, por los buenos ejemplos será provechosa. Y es de gusto, porque hay mucho del ridículo, que es lo

18. Para el plagio del Pinciano, véase el comentario de Mañero (Segunda parte, $\mathrm{n}$. 421, p. 520).

19. Ver McGrady, 1966, pp. 334-335, y las notas de Mañero, 2007, pp. 522-523. 
más que se ha de procurar en las farsas, porque lo tienen casi por fin y objeto (Segunda parte, p. 527).

Un juicio nada desacertado del teatro de la época, precisamente en los años de la gestación de la futura comedia nueva, que en pocos años convocará a las tablas a los graciosos y las fregonas.

Puede dudarse si podrían ser suyas las anécdotas y ajenos los sermones y disertaciones del largo pasaje. Pero la desmañada arquitectura de Sayavedra, sus incoherencias y algunas anécdotas plagiadas descaradamente ${ }^{20}$ nos hacen desconfiar de esta tesis. El pie forzado del hondo consejo moral no es el fuerte del novelista levantino, pero sí lo es el rellenar páginas y más páginas con todo el ripio que le viene a las manos. Unas veces acierta y otras fracasa como narrador: sabe contar una historia, es capaz de rápidos movimientos narrativos, pero no distingue el grano de la paja novelesca. Así, por ejemplo, después de la interminable crónica de las bodas regias (libro III, capítulo XI), despachará con una sola frase la transición al relato picaresco: «Volvamos a mis disparates, que me traían desatinado, y me pusieron donde yo merecía» (Segunda parte, p. 587). En cambio, pertenece al Pinciano la larga anécdota de la hospedera, que ocupa nada menos que tres páginas (pp. 529-531) y que sólo sirve para que Guzmán cobre «grande opinión en la compañía de hombre que en todo caso daba buen parecer, y que podría darle también en cosas de la farsa y aprovecharía con algunas invenciones» (pp. 531-532). Pero en la época estas historietas gustaban, porque, según veremos después, Quevedo adornará en el Buscón la carrera teatral de Pablos con otra historieta parecida protagonizada por una ignorante mesonera gallega (pp. 213-214), tan graciosa que será a su vez emulada por Luis Vélez de Guevara en el tranco Iv de El diablo Cojuelo ${ }^{21}$.

Destaca, sobre todo, el relato del aprendizaje del pícaro-actor Guzmancillo en la compañía histórica de Alonso de Heredia ${ }^{22}$. Curioso es, por ejemplo, el repaso de las dotes innatas de ese personaje para el oficio:

Acordé conmigo de no acordarme de mi amo y seguir mi pensamiento y el camino de Valencia con Heredia. Empezáronme a dar papeles de poco trabajo al principio, para que me fuese ejercitando; probaba en esto maravillosamente, como si no naciera para otra cosa; sin duda tenía partes grandes para el ejercicio cómico, porque vergüenza había años que no habitaba en mí; era expeditísimo en el hablar, no mal talle ni donaire, memoria prodigio-

20. Como la relatada en las pp. 527-528.

21. Comp. la nota de Cabo (Buscón, 214.45).

22. Según el DICAT, de las dos compañías con autores de apellido Heredia, entiendo que cabe deducir que el único que frecuentó Valencia fue Alonso, casado con María de Rojas y que tuvo compañía de veinte personas en torno a 1600. De abril de 1597 a julio de 1598 estuvo con su agrupación en la ciudad del Turia, al igual que en la primavera de 1599, coincidiendo con las bodas reales, aunque en marzo de 1600 giraba por Valladolid y Salamanca y en 1602 por Granada. No hay duda de que en una de esas visitas Luján de Sayavedra tuvo que entrar en contacto con ellos. 
sa. Por momentos me iban dando otros papeles de mayor primor, de quien colgaba todo el peso y llave de la farsa; pero en Madrid no osé salir al teatro, porque mi amo no me hiciese salir de la librea (Segunda parte, p. 533).

Y se relata el circunstanciado amorío con una actriz que debió ser moneda corriente en las compañías áureas:

Acabada la tragedia, desliceme de mis amigos y entreme al vestuario como solía, por ver a mi señora Isabela. Ofrecímonos mares y montes y quedé persuadido de asentar la plaza y seguir la compañía, que se partía luego a Valencia por la misma ocasión de las fiestas que se esperaban (p. 529).

El valenciano se detiene especialmente en la insaciable codicia de la ninfa: “Camino de Valencia tuve muchos lances con mi Isabela, que íbamos todos en un carro y de un acuerdo. Aficioneme tanto, que sin rienda ni tino me dejé llevar de mi locura» (p. 533); unas frases que Quevedo también remedará en su propia novela.

Pero el pasaje más interesante para nosotros del imitador de 1602 es justamente, ya en el capítulo Ix, la descripción de «lo que pasó con un mal poeta» (p. 543). Ese episodio aparece bien enhebrado con el relato de los amores de nuestro Guzmancillo metido a farandulero, entre digresiones sobre los celos -que ahorro al lector- y valiosas notas de localismo valenciano:

Cuatro días había que estábamos en Valencia, y sólo habíamos representado una vez. Andaban algunos galancetes perdidos para jugarme la pieza; ella era tan redomada, que ni yo podía estar seguro ni confiado; y así, por mi desgracia estaba celoso, que no hay amor ni celos, hijos perversos, viboreznos, de quien pudiera decir muchas maravillas [...]. Al segundo día de farsa ya andaban los galanes más solícitos, y mi enemiga menos desdeñosa que con los ojos llamaba aun los descuidados. Era carta vieja; había ya pisado otra vez, y aun muchas, el teatro de Valencia, y sabía bien la calle de la Mar, plaza de la Olivera, el Grau y sus Barracas, y el Regañón de la plaza de la Morera. [...] Acabada la farsa, salimos a nuestra posada, que teníamos en la misma plaza de la Olivera, y ya nos esperaban a la puerta della unos cuantos garzones. Entráronse con nosotros. A la conversación hube de ensanchar el corazón y soltalle las alhorzas, porque cupiesen estas pesadumbres, y aun hacelle de las tripas. Supe la condición de esta gente que, en enfadándose, no queda a vida representante, y han enviado muchos razonablemente acuchillados (pp. 543-549).

La caricatura del mal poeta dramático aparece precisamente encajada en medio de ese pasaje, lo que nos da idea de la habilidad narrativa de Luján, a pesar de sus torpes incisos:

Trabóse brava conversación; muchos ofrecimientos de paseo, y atajóla un gentil entremés de un señor poeta que, con una capa larga de bayeta, como portugués, preguntaba por el autor. Conociéronle los que allí estaban, 
y como le sabían el humor, sospecharon que traería alguna maldita farsa, como era verdad. Advirtieron al autor que no dejase de vella, porque le mataría de risa, y la hiciese leer ante todos.

Salió Heredia, y díjole:

-Pues ¿qué nos manda vuestra merced en su servicio? Yo soy el autor, y si vuestra merced nos trae algo de poesía, que ya sabemos que es famoso poeta, nos hará mucha merced, porque hay falta de farsas que sean buenas, y señaladamente para un lugar de tales gustos como Valencia, que hace temblar a cualquier autor (p. 549).

Salta a la vista en todo ello el conocimiento directo que del mundillo teatral poseía el autor del apócrifo guzmaniano, que no nos regatea detalles sobre el marketing teatral de la época, con las lecturas a prueba, la exhibición de un catálogo de piezas y la invocación de un título al uso, El cautivo engañoso:

Hízose el buen hombre muy alegre con tal acogimiento, y dijo:

-No repare vuestra merced en comedias, que le proveeré de todas las que hubiere menester, que dos tengo empezadas, y esta que aquí traigo, que sólo el nombre della dirá quien es.

-¿Cómo la intitula vuestra merced -dijo Heredia-, que mucho importa el buen título?

-Muchos nombres - dijo el poeta- se le pueden dar, pero me parece que le cuadra mucho El cautivo engañoso.

-Bonísimo -le dijo Heredia (pp. 549-550).

Ese autor de la época, un personaje histórico como ya se ha visto, confiere aquí una cierta pseudo-historicidad al propio Guzmán, un efecto reforzado, a renglón seguido, por la alusión a Gaspar de Porras y al crecido precio de las comedias destinadas a las tablas:

Vuestra merced nos haga merced de leella, que aquí está el señor Guzmán, que es hombre de buen gusto y le cometo el ver este negocio, y estaré a lo que dijere, y creo será extremada, por ser de su mano de vuestra merced.

-¿Cómo buena? - dijo el poeta-; ella lo dirá, que no pensaba dalla a ningún autor sino a Porras, que me tiene ofrecidos mil reales por cada farsa. -Léala vuestra merced -dijo Heredia-, que, siendo lo que pensamos no llorará vuestra merced a Porras (p. 550) ${ }^{23}$.

En cualquier caso, queda claro que Luján supo armar este entremés metateatral a base de irónicos diálogos, tras los que el pobre escritor aficionado queda finalmente ridiculizado.

Pero la mejor parte de esta escenita sale a relucir al final:

23. Sobre Porras o Porres véase la nota de Mañero, con bibliografía (Segunda parte, n. 536). Destaca ahí el dato de que esa agrupación trabajó en Valencia durante todo el verano de 1601. 
Sacó su envoltorio el triste poeta, que no debiera, y empezó con unos versos que no les debió de sacar de botica de sedas, según les hubo tan mal medidos; $y$, con todo, a cada redondilla levantaba los ojos y miraba a todos los oyentes, como si fuera un concepto milagroso. Todos estábamos perdidos de risa, y no había orden de disimulalla, hasta que él lo echó de ver, y muy corrido dijo:

-Yo creo que vuestras mercedes tienen hecho el estómago al verso de Lope de Vega, y no les parece nada bueno (p. 551).

El poetastro presume de una «jornada pastoril a la morisca de allá de África, que es una maravilla, porque los poetas aún no habían advertido que entre los moros hay pastores, y es invención nueva», un disparate que da lugar a las cómicas objeciones de los presentes (pp. 551-552) y una secuencia que imitará Quevedo en su momento. El narrador remata entonces la grotesca lectura:

Entrose por ella como por viña vindimiada, porque la sabía de coro; pero teníamos a un dedo de reventar de risa. Uno de los caballeros hijos de vecino que venían al olor de mi probática, disparó en una risa que no la pudo sostener; y como no era menester brindarnos, salimos todos al paraje, que nuestro poeta se había hecho un matachín. Envolvió sus papeles y metiólos en las calzas, haciendo grande queja de la burla, y diciendo que no sabíamos qué eran farsas y versos. Colose la escalera abajo y dejonos que reír para todo el año (pp. 553-554).

Para dejarnos a solas con Guzmán, que, con el fin de costearse sus amores, terminará capeando de noche por las calles de Valencia y dará, así, con sus huesos en las galeras de su majestad.

En suma, las coordenadas de su historieta teatral son históricas: el novelista acertó al elegir a Heredia como referencia, al menos a tenor de los elogios que Lope hizo de ese empresario ${ }^{24}$; las comedias de cautivos fueron populares a finales del xvI; el incesante consumo de piezas en los corrales hacía que los poetas aficionados improvisaran un repertorio; los empresarios aguardaban ansiosos a esos proveedores y se creó una dialéctica de oferta y demanda, con subidas tarifas y suculentas ganancias; los dramaturgos mediocres trataban de colocar su stock y los autores los esquivaban o se burlaban de ellos en chuscas sesiones de lectura. Podemos intuir entonces que, fuera quién fuera Luján de Sayavedra, debió ser un entendido en teatro o, al menos, un buen aficionado amigo de actores y autores, seguramente incapaz de escribir una comedia él mismo, pero quizás lo bastante vivo como para calibrar el modo de componer obritas menores: así, en el capítulo in del libro segundo, describe el episodio del cocinero y su amante como materia que permitiría «hacer un buen entremés de farsa» (p. 284) ${ }^{25}$. Y en otro lugar

24. Véase la cita aducida por Mañero (Segunda parte, p. 532, n. 463).

25. Mañero conjetura acertadamente al pie que el plagiario alude así a los palos finales de los entremeses de ese tiempo (Segunda parte, n. 100). 
anota otro dato revelador por boca de su Guzmán: «Acordábame que había de volver a mis trapos viejos de sacristán de aldea, que aunque no representara mal con ellos la comedia del Dómine Lucas, pero sí la del Caballero sastres (p. 532). El primer título es el de una pieza de Lope, estrenada por Melchor de Villalba posiblemente a finales de $\operatorname{sigl}^{26} \mathrm{y}$ publicada en 1621; el segundo es atribuido por La Barrera a un licenciado Juan de la Flor de la Universidad de Salamanca (1968, p. 161).

Como muestran la Comedia erudita de Sepúlveda (c. 1565) y, desde luego, el estudio clásico de Sentaurens (1984), la vida teatral sevillana era pujante en las décadas finales del xvi. Sin embargo, Alemán no acusó demasiado ese desarrollo en su magistral novela, todo lo más Guzmán dice acudir a los corrales como espectador en varias ocasiones, y en la primera de ellas solamente menciona esa circunstancia para destacar su incomodidad entre los demás asistentes (II, I, 1), otra vez para robar (II, II, 4) y las dos restantes como un pasatiempo (II, II, 9; II, III, 5). Además, es muy probable que esquivara, entre otros, el oficio de actor para su protagonista, justamente para condenarlo a una existencia individualista y marginal, que le impedía proyectarse hacia la industria teatral, las compañías o el público, tres vías de socialización un tanto incongruentes con el camino de insolidaridad, ensimismamiento y alienación elegido por el auténtico personaje alemaniano, un pícaro en estado puro, atalayado en su personal moralismo, encapsulado en su teatro interior, confesión o apología personal ${ }^{27}$.

Este vacío permitió al más mundano Luján explorar, tempranamente y con cierto detalle, unos territorios novelescos nuevos, el del pícaro-actor y el de la sátira del mal dramaturgo. Por otro lado, de ser Juan Felipe Mey el plagiario, según defiende Laguna, una curiosa maraña de circunstancias rodearía a este personaje histórico, aunque es difícil atar cabos. Para empezar, la novela apócrifa iba dedicada a Gaspar Mercader y Carroz, señor de Buñol y Siete Aguas y presidente provisional de la Academia de los Nocturnos durante algunas sesiones en 1593, un círculo al que también perteneció Juan Martí, el abogado valenciano al que Alemán acusó del plagio en virtud del hipotético anagrama Martí Luxán = Juan Martí. Mercader, conocido en esa academia como Relámpago y autor de

26. El Fénix escribió para ese autor desde los tiempos de Alba de Tormes, hacia 1594 (véase Ruano de la Haza, 2008, p. 35), y hasta 1602. La última fecha consta en el estudio de García Reidy (p. 81), quien además nos informa de que Lope no anotó los títulos de sus comedias representadas ante Felipe III durante los fastos de las dobles bodas en Denia en febrero de 1599 (Felipe con Margarita de Austria, y su hermana Isabel Clara Eugenia con Alberto, archiduque de Austria). Sea como fuere, Villalba trabajó con su compañía en Valencia “durante gran parte de 1598» (p. 81) y es muy posible que el escritor levantino del apócrifo de 1602 viera en Valencia, o incluso en Denia, El dómine Lucas, escenificada por la agrupación de ese director teatral. Profeti y García García anotan, además, que, por ese tiempo, la gente de Villalba alternaba con la compañía de Heredia en La Olivera (2004, p. 166, n. 737-744,), de manera que nuestro misterioso novelista pudo armar su episodio con sus recuerdos valencianos de la temporada teatral de 1599.

27. Maravall y Cavillac (2010) han analizado la crisis social que ejemplifica Alfarache. 
la novela pastoril El prado de Valencia (1600), fue un cortesano y poeta reconocido en la ciudad del Turia y después en Madrid, y amigo, además, de los dramaturgos valencianos de esos años: Tárrega, Guillén de Castro, Aguilar, Beneito, Virués y Rey de Artieda. Otro Mey, Pedro Patricio, fue el editor de las obras de Mercader en Valencia. En los Nocturnos debió representarse teatro y en la Valencia de fines de siglo proliferaron los corrales, las compañías y los dramaturgos. El mismísimo Lope de Vega se inspiraría en ese panorama teatral, y en especial en la producción dramática de Tárrega, pues ese canónigo supo prefigurar la comedia nueva en El prado de Valencia, de 1589. No es difícil pensar, por tanto, que el novelista falsario, que pertenecía seguramente a ese ambiente, viviese u oyese contar una anécdota real del tenor de la que relata en su novela.

Entre paréntesis, el Fénix de los Ingenios compuso Los locos de Valencia en esa ciudad en 1590, una obra que pone en escena a un poeta loco y desarrolla en su último acto unos entremesillos internos de locos-figuras que no andan del todo lejos de nuestro episodio del dramaturgo orate. Tropé, editora de la pieza, destaca el metateatro, una "teatralidad que invade la comedia» por medio de una boda fingida con público sentado en bancos y «dos entremeses de locos fantoches», que, según esa estudiosa, pertenecen a la tradición de los bailes de locos, que asumían la estructura de un desfile o «revista de personajes estereotipados ante un personaje que cumple la función de juez». Los enfermos, en consecuencia, ejercen como verdaderos comediantes "que representan en escena la comedia de sus locuras» (Los locos, pp.

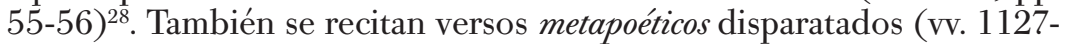
1130). Pero el detalle más interesante para nosotros es el personaje del poeta loco Belardo, alter ego lopiano, matemático, astrólogo, humanista y poeta demente con rasgos positivos, que otro carácter resume en un parlamento (vv. 2549-2558) ${ }^{29}$. Con todo, ni el Fénix de los Ingenios ni nadie en esos años llegó todavía a intuir como el autor de la falsa Segunda parte del Guzmán la figura del autor teatral ridículo, con su mala comedia a cuestas.

Tres lustros después, el sagaz Quevedo sabrá sacar tajada del nuevo filón metaliterario en su Buscón: trasladará el episodio valenciano a Castilla, pero, sobre todo descartará por completo los sermones y moralinas y se ceñirá al puro esqueleto novelesco, como muestran incluso la extensión de los capítulos -hasta 90 páginas- y sus títulos en el apócrifo:

28. Sería interesante considerar este deshilvanado desfile lopiano como un antecedente lejano de los desfiles de figuras barrocos del siglo siguiente. Es evidente que el joven Lope tenía buenas ideas, pero carecía de la destreza teatral para llevarlas a su mejor término: los locos temáticos y sus manías no están ahí bien perfilados, el desfile aparece poco desarrollado y la caricatura del poeta, a pesar de dedicarle algunas páginas, es un mero esbozo. La obra presenta, en fin, las inconsistencias que Joan Oleza y otros han visto en ese primer Lope de Vega.

29. Bien descrito por Tropé en su introducción a Los locos, pp. 61-63. 
Capítulo vir. Trata Guzmán cómo mudó de parecer de hacerse fraile y asentó de nuevo con otro amo, y cómo, por haber leído libros profanos y por amores de una farsanta, quiso profesar el arte cómico.

Capítulo viri. En que prosigue Guzmán su designio, asienta en la compañía de Heredia y cuenta lo que le sucedió camino de Valencia.

Capítulo ix. En que cuenta Guzmán los celos que tuvo de Isabela, y lo que pasó con un mal poeta, y cómo se atrevió a capear por acudir a las locuras de su ninfa.

Y en la novela de 1626, donde el motivo del mal dramaturgo se desdoblará en dos episodios separados por muchas páginas, sin duda para explotarlo mejor: primero, en los capítulos 2-3 del libro II, se repasa el currículum poético de un «clérigo muy viejo en una mula» y se comenta una ridícula comedia suya (Buscón, pp. 114-117; cita en 114); y luego, en el capítulo 9 del libro III, donde se narran las andanzas de Pablos como actor e incluso como bisoño dramaturgo, bajo un título con cierto aire de desfile de figuras: «En que se hace representante, poeta y galán de monjas» (Buscón, pp. 208-219) ${ }^{30}$, Y, desde luego, Quevedo nos ahorra el plomizo capítulo x del apócrifo, una crónica de las bodas reales en Valencia. Además, según veremos, volverá a sacar a relucir el motivo del poeta orate y antisocial de sus premáticas juveniles y cruzará esa caricatura con las figuras del vate a lo divino y del aficionado a emborronar comedias.

En el primer pasaje citado remeda la técnica de hacer que el delirante escritor, que resulta ser sacristán de Majadahonda, ofrezca su dudosa mercadería, teatral y no teatral:

-¿No? -dijo al mismo punto-; pues oya v. md. un pedacito de un librillo que tengo hecho a las once mil vírgines, adonde a cada una he compuesto cincuenta otavas, cosa rica.

Yo, por escusarme de oír tanto millón de otavas, le supliqué que no me dijese cosa a lo divino. Y así, me comenzó a recitar una comedia que tenía más jornadas que el camino de Jerusalén. Decíame:

-Hícela en dos días, y éste es el borrador.

Y sería hasta cinco manos de papel. El título era El arca de Noé. Hacíase toda entre gallos y ratones, jumentos, raposas, lobos y jabalíes, como fábulas de Isopo. Yo le alabé la traza y la invención, a lo cual me respondió:

-Ello cosa mía es, pero no se ha hecho otra tal en el mundo, y la novedad es más que todo; y, si yo salgo con hacerla representar, será cosa famosa.

-¿Cómo se podrá representar -le dije yo-, si han de entrar los mismos animales, y ellos no hablan?

-Esa es la dificultad, que a no haber ésa, ¿había cosa más alta? Pero yo tengo pensado de hacerla toda de papagayos, tordos y picazas, que hablan, y meter para el entremés monas (Buscón, pp. 115-116).

30. Aunque el episodio que nos interesa concluye abruptamente en la p. 214 . 
Agrega también una nota cómica que, desde luego, no estaba en el pseudo-Guzmán, la del zascandil que piensa que del roce con los escritores famosos se le pegará el talento:

-Hombre soy yo que he estado en un aposento con Liñán, y he comido más de dos veces con Espinel.

Y que había estado en Madrid tan cerca de Lope de Vega como lo estaba de mí, y que había visto a don Alonso de Ercilla mil veces, y que tenía en su casa un retrato del divino Figueroa, y que había comprado los gregüescos que dejó Padilla cuando se metió fraile, y que hoy día los traía, y malos. Enseñólos, y dioles esto a todos tanta risa, que no querían salir de la posada (Buscón, p. 123).

Pero será casi al final de la novela, en el mencionado capítulo 9 del libro tercero, donde Quevedo echará el resto en el asunto que nos ocupa, preparando la nueva aventura con unas breves líneas circunstanciales:

Topé en un paraje una compañía de farsantes que iban a Toledo. Llevaban tres carros, y quiso Dios que, entre los compañeros, iba uno que lo había sido mío del estudio en Alcalá, y había renegado y metídose al oficio. Díjele lo que me importaba ir allá y salir de la corte; y apenas el hombre me conocía con la cuchillada, y no hacía sino santiguarse de mi per signum crucis. Al fin, me hizo amistad, por mi dinero, de alcanzar de los demás lugar para que yo fuese con ellos (Buscón, p. 208).

El episodio amoroso del prolijo Guzmán apócrifo quedará reducido en la novela de Quevedo a poco más que un escarceo con la esposa de un cómico. No obstante la prisa, el madrileño tendrá tiempo para detenerse en el intríngulis erótico, en la libertad de los cómicos y en el motivo del maridillo postizo, materias todas muy de su gusto:

Íbamos barajados hombres y mujeres, y una entre ellas, la bailarina, que también hacía las reinas y papeles graves en la comedia, me pareció estremada sabandija. Acertó a estar su marido a mi lado, y yo, sin pensar a quien hablaba, llevado del deseo de amor y gozarla, díjele:

-A esta mujer, ¿́por qué orden la podremos hablar, para gastar con su merced unos veinte escudos, que me ha parecido bien por ser hermosa?

-No me lo está a mí el decirlo, que soy su marido -dijo el hombre-, ni tratar deso; pero sin pasión, que no me mueve ninguna, se puede gastar con ella cualquier dinero, porque tales carnes no tiene el suelo, ni tal juguetoncica.

Y diciendo esto, saltó del carro y fuese al otro, según pareció, por darme lugar que la hablase. Cayome en gracia la respuesta del hombre, y eché de ver que éstos son de los que dijera algún bellaco que cumplen el preceto de san Pablo de tener mujeres como si nos la tuviesen, torciendo la sentencia en malicia. Yo gocé de la ocasión, habléla, y preguntóme que adónde iba, y algo de mi vida. Al fin, tras muchas palabras, dejamos concertadas para Toledo las obras (Buscón, pp. 208-209). 
No menos interesantes son los demás detalles que el satírico madrileño ofrece sobre una carrera de actor en el Siglo de Oro:

Íbamonos holgando por el camino mucho. Yo, acaso, comencé a representar un pedazo de la comedia de San Alejo, que me acordaba de cuando muchacho, y representelo de suerte que les di cudicia. Y sabiendo, por lo que yo le dije a mi amigo que iba en la compañía, mis desgracias y descomodidades, díjome que si quería entrar en la danza con ellos. Encareciéronme tanto la vida de la farándula, y yo, que tenía necesidad de arrimo, y me había parecido bien la moza, concerteme por dos años con el autor. Hícele escritura de estar con él, y diome mi ración y representaciones. Y con tanto, llegamos a Toledo. Diéronme que estudiar tres o cuatro loas, y papeles de barba, que los acomodaba bien con mi voz. Yo puse cuidado en todo, y eché la primera loa en el lugar. Era de una nave, de lo que son todas, que venía destrozada y sin provisión; decía lo de «este es el puerto», llamaba a la gente «senado», pedía perdón de las faltas y silencio, y entreme. Hubo un víctor de rezado, y al fin parecí bien en el teatro (Buscón, pp. 209-210).

Pero no le basta con anotar esos detalles o con criticar las mañas rutinarias de las loas, por entonces ya casi moribundas ${ }^{31}$, pues el satírico se demora en la figura metateatral en ciernes, la del desmañado actor-poeta:

Representamos una comedia de un representante nuestro; que yo me admiré de que fuesen poetas, porque pensaba que el serlo era de hombres muy doctos y sabios, y no de gente tan sumamente lega. Y está ya de manera esto, que no hay autor que no escriba comedias, ni representante que no haga su farsa de moros y cristianos; que me acuerdo yo antes, que si no eran comedias del buen Lope de Vega, y Ramón, no había otra cosa (Buscón, p. 210).

Según la nota de Cabo, los autores que escriben comedias son los así citados por Agustín de Rojas en la «Loa de la comedia» de El viaje entretenido (n. 210.17), pero quizás habría que añadir a esa nómina a todos los perfectos desconocidos que estropeaban piezas ajenas en las compañías de la legua. Las farsas de moros y cristianos podrían ser piezas del último cuarto del xvi como las dos comedias de cautivos conocidas de Cervantes o Los hechos de Garcilaso de la Vega y moro Tarfe de Lope (1579-1583), por ejemplo. Ese antes debe remitir, en cambio, a los últimos años o a la vuelta del siglo, a tenor de la referencia a Alonso Remón, que seguramente dejó de componer para los corrales hacia $1605^{32}$, aunque el Buscón se escriba y difunda pocos años después, pues para el joven Quevedo una distancia de un lustro podía parecer entonces un lapso considerable de tiempo. La gente tan sumamente lega son los atrevidos faranduleros que aprovechaban la racha, y el fruto de su trabajo será una desastrosa comedieja:

31. Un especialista en ellas como Agustín de Rojas Villandrando las definió en su Viaje entretenido de 1603 como "malas y un disparate todas» (p. 63).

32. Ver Fernández Nieto, 1974, p. 37. 
Al fin, hízose la comedia el primer día, y no la entendió nadie; al segundo, empezámosla, y quiso Dios que empezaba por una guerra, y salía yo armado y con rodela, que, si no, a manos de mal membrillo, tronchos y badeas, acabo. No se ha visto tal torbellino, y ello merecíalo la comedia, porque traía un rey de Normandía, sin propósito, en hábito de ermitaño, y metía dos lacayos por hacer reír; y al desatar de la maraña, no había más de casarse todos, y allá vas. Al fin, tuvimos nuestro merecido. Tratamos todos muy mal al compañero poeta, y yo principalmente, diciéndole que mirase de la que nos habíamos escapado y escarmentase (Buscón, pp. 210-211).

Esa reseña teatral pone de manifiesto una burda imitación de una comedia nueva al uso: confusión expositiva, mala traza y caos argumental -una maraña - en lugar de enredo, disfraces sin propósito, nada menos que dos graciosos y el final tópico con bodas en cadena llevado igualmente a la exageración.

Y va sin decir cuál podía ser la traza de los actores-poetas de ocasión para componer piezas de aliño sobre la marcha:

Díjome que, jurado a Dios, que no era suyo nada de la comedia, sino que de un paso tomado de uno, y otro de otro, había hecho aquella capa de pobre de remiendo y que el daño no había estado sino en lo mal zurcido. Confesóme que los farsantes que hacían comedias todo les obligaba a restitución, porque se aprovechaban de cuanto habían representado, y que era muy fácil, y que el interés de sacar trecientos o cuatrocientos reales les ponía aquellos riesgos. Lo otro, que, como andaban por esos lugares, les leían unos y otros comedias:

-Tomámoslas para verlas, llevámonoslas y, con añadir una necedad y quitar una cosa bien dicha, decimos que es nuestra.

Y declarome como no había habido farsante jamás que supiese hacer una copla de otra manera (Buscón, p. 211).

En palabras que encierran una de esas rápidas semblanzas satíricas profesionales que tan caras serían algo después al Quevedo de los Sueños, por ejemplo. El bosquejo produce la fuerte impresión de una cosa real, aunque cargando las tintas contra los cómicos más chapuceros y oportunistas. Si en el caso del clérigo de Majadahonda se subrayaban su creatividad torrencial, su torpeza e ignorancia, aquí destacan el plagio y la improvisación teatrales, hechos por lo demás históricos ${ }^{33}$. La imagen de la capa de pobre, a modo de manta trapera, resulta elocuente, y Quevedo se goza en retratar otra vez al escritorzuelo-actor en plena taracea de versos y pasos e incapaz, como todos sus congéneres, de hacer una copla de otra manera ${ }^{34}$.

33. Véanse, entre otros, los trabajos de Sánchez Mariana (1993) y Vega GarcíaLuengos (1998) y los volúmenes coordinados respectivamente por Blasco (2010), Arellano (2004) y Vitse (1998).

34. Por ejemplo, Cervantes se burló, en su Viaje del Parnaso (1614), del sastre Agustín Castellanos, protegido de Lope, de un zapatero «de obra prima» y de un tundidor, todos 
Pablos, después de escuchar tan equívocos consejos, que más bien deberían escarmentarlo, se engolosina con los buenos dineros y se lanza a escribir: «No me pareció mal la traza, y yo confieso que me incliné a ella, por hallarme con algún natural a la poesía; y más, que tenía yo conocimiento con algunos poetas, y había leído a Garcilaso; y así, determiné de dar en el arte» (Buscón, p. 211). Nada más lejos, probablemente, de los comienzos poéticos del propio Quevedo, que aquí remite deliberadamente a fuentes literarias bastante trasnochadas: Garcilaso de la Vega y la rara Comedia de San Alejo (1579) ${ }^{35}$; pero sí cabe pensar que se trate de un mundillo que nuestro satírico debió conocer desde sus años universitarios ${ }^{36}$, pues no olvidemos que la década de 1600 1610 fue verdaderamente prodigiosa para el teatro español. Acaso no desea, como tampoco lo hará Cervantes, hacer sangre con las obras de escritores contemporáneos, o quizás quiere parecer realista, con unas referencias lejanas que resulten cómicamente anticuadas después de 1600. Sea como fuere, escribe siempre con el azote satírico a mano: otra vez, el trabar conocimiento ('amistad') con algunos poetas como un dudoso estímulo artístico, o ese dar en el arte como por azar y por necesidad, y no por una vocación clara, apuntan a la carrera poética y teatral sobrevenida de un pícaro oportunista que ejerce como versificador de ocasión, entre otros muchos oficios y siempre pro pane lucrando, aunque hable de arte. El elitista y cultísimo Quevedo no pudo por menos de sonreír sarcásticamente al escribir esas líneas...

Como siempre, causa admiración su capacidad de síntesis, pues pocas líneas después dibuja una fugaz carrera de actor:

Y con esto y la farsanta y representar, pasaba la vida. Que pasado un mes que había que estábamos en Toledo, haciendo comedias buenas y enmendando el yerro pasado, ya yo tenía nombre, y habían llegado a llamarme Alonsete, que yo había dicho llamarme Alonso; y por otro nombre me llamaban el Cruel, por serlo una figura que había hecho con gran aceptación de los mosqueteros y chusma vulgar. Tenía ya tres pares de vestidos, y autores que me pretendían sonsacar de la compañía. Hablaba de entender de la comedia, murmuraba de los famosos, reprehendía los gestos a Pinedo, daba mi voto en el reposo natural de Sánchez, llamaba bonico a Morales, pedíanme el parecer en el adorno de los teatros y trazar las apariencias. Si alguno venía a leer comedia, yo era el que la oía (Buscón, pp. 211-212).

Estas frases no tienen desperdicio y recogen todas las facetas profesionales: la actuación y su comentario, la familiaridad gremial con los colegas, el fichaje de los actores más hábiles por otras agrupaciones,

dramaturgos sobrevenidos (II, vv. 403-423; pp. 1257-1258). Sobre el citado Castellanos, un analfabeto al que el Fénix ayudaba a componer comedias, véase San Román (1935, cap. v).

35. Comp. la nota al pie 209.9 de Cabo al Buscón. Perromat, 2009, p. 262, ha aludido precisamente al vate toledano como fuente de muchas citas teatrales en el Siglo de Oro.

36. Piénsese en los apuntes del florentino Girolamo da Sommaia, que retrata esa animada vida teatral en la Salamanca de los años 1599-1607 (Diario de un estudiante...). 
la escenografía, el comadreo de los desvanes, los mosqueteros y chusma vulgar... Entresaco la nota final de la lectura de piezas a prueba, que remite a su modo al gracioso episodio neoguzmaniano ya visto.

Pero Quevedo, dramaturgo y poeta él mismo, no puede evitar interesarse especialmente por la escritura. El camino creativo -por llamarlo algo- de Alonsete el Cruel es, a grandes rasgos, el mismo del clérigo de Majadahonda, esto es, del entremés y el romance a la endeble comedia de santos o al auto sacramental, a los que llama divina cosa con retintín:

$\mathrm{Al}$ fin, animado con este aplauso, me desvirgué de poeta en un romancico, y luego hice un entremés, y no pareció mal. Atrevíme a una comedia, y porque no escapase de ser divina cosa, la hice de Nuestra Señora del Rosario. Comenzaba con chirimías, había sus ánimas de purgatorio y sus demonios, que se usaban entonces, con su «bu, bu» al salir, y «rri, rri» al entrar; caíale muy en gracia al lugar el nombre de Satán en las coplas, y el tratar luego de si cayó del cielo, y tal. En fin, mi comedia se hizo, y pareció muy bien (Buscón, p. 212) ${ }^{37}$.

Los demonios que se usaban entonces pueden muy bien ser, por ejemplo, los de los autos y comedias a lo divino -como la escrita por Pablosde Lope y otros contemporáneos. El mismo Fénix hace aparecer a Satán en 23 de sus comedias de distintas épocas, y el ángel caído comparece hasta en 120 piezas de muchos autores desde 1594, según Moreno Mendoza. Ese estudioso describe su apariencia típica -túnica de llamas, cola, una piel y cuernos, y precedido muchas veces de pólvora y cohetes (2009, pp. 152-153)-, pero no los sonidos onomatopéyicos a los que alude Quevedo.

Por otra parte, salta a la vista que, al deslindar el mal poeta del modelo lujaniano en dos aficionados distintos, el colega actor y Pablos mismo, Quevedo presenta dos casos opuestos de éxito y fracaso teatral, pero ambos reveladores del cinismo de los actores-dramaturgos contemporáneos, que supeditaban la creatividad al puro beneficio y que, además, se servían, según Quevedo, de artimañas, plagios y tópicos facilones para rellenar sus malas comedias. En realidad, el triunfo de Pablillos no tiene que ver con la calidad de su obra, sino con la elección de un tema espectacular y sacro, justamente banalizado por él. Incluso podría suceder que Quevedo deseara contrastar el fiasco del actor por no atenerse a la arquitectura canónica de la comedia con el acierto del pícaro con una pieza no mucho más sólida, pero que halaga el gusto del populacho. En suma, la carrera de un dramaturgo respondía a imperativos comerciales y estaba en manos del denostado vulgo de los corrales, que carecía de criterios artísticos.

Tengamos en cuenta también que el propio satírico madrileño se ensayaría justamente con sus entremeses y más tarde, en tiempos de Olivares, con una comedia, aunque no de santos, sino de hombres de

37. Comp. la nota de Cabo sobre estos tópicos teatrales (Buscón, n. 212.30). 
estado y anti-maquiavélica, Cómo ha de ser el privado. Sin duda Quevedo -a tenor de lo que aquí escribe- desdeñaba el manoseo vulgar de las cosas sacras y la invocación populachera a Satán. ¿Qué podía pensar, en efecto, el compositor de jácaras de quienes llegaron a divinizar al mismísimo Escarramán?

Prosigue entonces nuestro novelista con su conocida sátira antipetrarquista, asociando la más exquisita escuela poética quinientista, ya en cierto descrédito después de 1600, con la venalidad de la poesía por encargo:

No me daba manos a trabajar, porque acudían a mí enamorados, unos por coplas de cejas, y otros de ojos, cuál soneto de manos, y cuál romancico para cabellos. Para cada cosa tenía su precio, aunque, como había otras tiendas, porque acudiesen a la mía, hacía barato. ¿Pues villancicos? Hervía en sacristanes y demandaderas de monjas; ciegos me sustentaban a pura oración, ocho reales de cada una; y me acuerdo que hice entonces la del Justo Juez, grave y sonorosa, que provocaba a gestos (Buscón, p. 212).

Y, frente al más limitado pseudo-Guzmán, Quevedo se dará maña para remedar versos paródicos en imitación de los coplones baratos de la época (Buscón, pp. 212-213), unos absurdos ripios que dan idea de cómo se componía una comedia a base de verdadero cascajo poético. Aunque, paradójicamente, esa bazofia teatral asienta la fama semi-profesional del dramaturgo Alonsete-Pablos: una vez más, otro hábil truco del arribista embaucador, ahora metido a poeta.

Para que no falte nada, Quevedo nos relata la mencionada anécdota de la moza gallega del mesón donde se hospeda Pablos. La historieta no tiene más interés para nosotros que mostrarnos a Pablos en plena composición de una comedia ripiosa y de aparato y a la criada en el típico trance cómico de confundir verdad y ficción teatral:

Sucedióme un día la mejor cosa del mundo, que, aunque es en mi afrenta, la he de contar. Yo me recogía en mi posada, el día que escribía comedia, al desván, y allí me estaba y allí comía; subía una moza con la vianda, y dejábamela allí. Yo tenía por costumbre escribir representando recio, como si lo hiciera en el tablado. Ordena el diablo que, a la hora y punto que la moza iba subiendo por la escalera, que era angosta y escura, con los platos y olla, yo estaba en un paso de una montería, y daba grandes gritos componiendo mi comedia; y decía:

Guarda el oso, guarda el oso,

que me deja hecho pedazos,

y baja tras ti furioso;

que entendió la moza - que era gallega-, como oyó decir «baja tras ti» $\mathrm{y}$ «me deja», que era verdad, y que la avisaba. Va a huir y, con la turbación, písase la saya, y rueda toda la escalera, derrama la olla y quiebra los platos, y sale dando gritos a la calle, diciendo que mataba un oso a un hombre. Y, por presto que yo acudí, ya estaba toda la vecindad conmigo preguntando por el oso; y aun contándoles yo como había sido ignorancia de la moza, porque era lo que he referido de la comedia, aun no lo querían creer; no comí aquel 
día. Supiéronlo los compañeros, y fue celebrado el cuento en la ciudad. Y destas cosas me sucedieron muchas mientras perseveré en el oficio de poeta y no salí del mal estado (Buscón, pp. 213-214).

Pablos casi logra ser autor de fama -inferimos que podría haberlo sido, en desmedro de los dramaturgos célebres de esos años, nombrados poco antes- y remata su aventura dramática con una desvergonzada reflexión: «Estaba viento en popa con estas cosas, rico y próspero, y tal, que casi espiraba ya a ser autor» (Buscón, p. 213). Pero las cosas vuelven a torcerse:

Sucedió, pues, que a mi autor -que siempre paran en esto-, sabiendo que en Toledo le había ido bien, le ejecutaron no sé por qué deudas y le pusieron en la cárcel, con lo cual nos desmembramos todos y echó cada uno por su parte. Yo, si va a decir verdad, aunque los compañeros me querían guiar a otras compañías, como no aspiraba a semejantes oficios y el andar en ellos era por necesidad, ya que me vía con dineros y bien puesto, no traté de más que de holgarme. Despedíme de todos; fuéronse, y yo, que entendí salir de mala vida con no ser farsante, si no lo ha v. md. por enojo, di en amante de red, como cofia, y por hablar más claro, en pretendiente de Antecristo, que es lo mismo que galán de monjas. Tuve ocasión para dar en esto porque una, a cuya petición había yo hecho muchos villancicos, se aficionó en un auto del Corpus de mí, viéndome representar un san Juan Evangelista (que lo era ella). Regalábame la mujer con cuidado y habíame dicho que sólo sentía que fuese farsante, porque yo había fingido que era hijo de un gran caballero, y dábala compasión (Buscón, pp. 214-215).

Donde nuestro novelista conecta el estatuto social del pícaro con el del actor, pues Pablos irónicamente piensa cambiar de vida con dejar de ser farsante, lo que resulta absurdo, porque, en definitiva, tanto daba ser actor que pícaro o que pícaro-actor y mal dramaturgo. Farsante siempre, la monja se enamora del actor que hace de san Juan y él inventa otro de sus embustes de arribista social. Tampoco pasa desapercibido el modo en que Quevedo anuda los dos episodios, el teatral y el eróticoconventual, a base de hacer acudir a la hermana como espectadora a un auto sacramental.

Según hemos visto, el motivo original del mal poeta de Luján se ha multiplicado por tres en el Buscón y se ha interiorizado: la sátira del clérigo letraherido de Majadahonda, la tentativa fallida del compañero actor de componer una comedia y el ensayo más afortunado del propio Pablos. Éste también insiste en compaginar el quehacer de poeta a secas con el de mal comediógrafo, y en todos los casos Quevedo destaca la ignorancia, el pragmatismo y la venalidad de los escritores aficionados. Trata, además, para apurarlo todo, el tema desde el punto de vista de los transmisores -actores y actores-dramaturgos- y del creador poético y teatral. Y no pierde tampoco comba a la hora de transformar la ceñida viñeta del pseudo-Guzmán en general chacota de la literatura vulgar de en torno a 1600, a menudo con muestras concretas: chanzonetas y vi- 
llancicos, interminables comedias de santos, entremeses, sonetos, redondillas, conceptos espirituales, plegarias de ciego, adocenadas loas, malos comediones bíblicos, romancicos, versos líricos de circunstancias, coplas de cautivos y autos sacramentales. Es decir, sigue el norte metateatral apuntado por el Guzmán vicario, aunque amplificando todos los motivos satíricos, asumiendo nuevas perspectivas y añadiendo versos paródicos.

Finalmente, importa hacer una consideración más, como a vista de pájaro: Luján de Sayavedra intuyó, quizás con ligereza e inconsciencia, pero muy tempranamente, cuando la industria teatral estaba en pleno auge, que el teatro corría parejo a la novela. Muchas veces se ha afirmado que Quevedo elaboraba sus sátiras y alegorías novelescas a modo de un espectáculo, de un entremés de figuras o de un theatrum mundi, pero el entonces joven satírico beneficiaría el mismo venero que Luján en el Buscón sin percatarse demasiado de las posibilidades de superponer esencialmente teatro y novela. Sin embargo, en Los sueños (escritos entre 1605 y 1622 y publicados en 1627), no sólo se percibe un giro en la producción quevedesca hacia una gravedad esencial, sino que el escritor reparó con más claridad en el hondo parentesco entre los dos géneros y modos de traducir la realidad, aunque también se olvidará para siempre de la novela como tal, si dejamos al margen el innovador relato total que es La hora de todos ${ }^{38}$.

Desde 1605 empezará a esbozarse el tan fructífero como inquietante contraste cervantino y barroco entre la realidad y la ficción, sea ésta de la naturaleza que sea y lo sea tanto al nivel de la literatura como al de la vida. Pensemos que ya el segundo Quijote de 1615 planteó esta cuestión en todos sus puntos: literatura - novela y teatro-, vida y falsificación vital de un mundo reducido a sus rituales, protocolos y apariencias, en el que los seres humanos conscientes y auténticos deben buscar su verdadero camino. La imagen de la compañía de la legua que viaja de un pueblo a otro sin quitarse los disfraces para ganar tiempo es inequívoca desde el título del capítulo: «De la estraña aventura que le sucedió al valeroso don Quijote con el carro o carreta de Las Cortes de la Muertes (II, 11). Basta pensar que cada situación que se ofrece a la vista del caballero orate tiene el valor de ser una faceta más del caleidoscopio que es esa complejísima novela, y la irrupción de la carreta de los actores no va a ser menos en este punto: en un juego de muñecas rusas, se encara al de la Triste Figura con una escena entre real y ficticia, entre teatral y filoteatral, entre literaria y real (puesto que es, ante todo, ficción dentro de la novela de 1615). Y no es casualidad que los comediantes vistan justamente los ropajes de las Cortes de la Muerte, una alegoría universalizante y barroquísima, y que el pasaje -y perdonéseme la larga cita- comience precisamente como una pesadilla, aunque luego se desvele su sentido:

38. De Cos Ruiz ha subrayado, por ejemplo, la idea del teatro o entremés del mundo en esa obra quevediana, con citas harto reveladoras (2002, p. 10). 
Responder quería don Quijote a Sancho Panza, pero estorbóselo una carreta que salió al través del camino cargada de los más diversos y estraños personajes y figuras que pudieron imaginarse. El que guiaba las mulas y servía de carretero era un feo demonio. Venía la carreta descubierta al cielo abierto, sin toldo ni zarzo. La primera figura que se ofreció a los ojos de don Quijote fue la de la misma Muerte, con rostro humano; junto a ella venía un ángel con unas grandes y pintadas alas; al un lado estaba un emperador con una corona, al parecer de oro, en la cabeza; a los pies de la Muerte estaba el dios que llaman Cupido, sin venda en los ojos, pero con su arco, carcaj y saetas. Venía también un caballero armado de punta en blanco, excepto que no traía morrión ni celada, sino un sombrero lleno de plumas de diversas colores. Con estas venían otras personas de diferentes trajes y rostros. Todo lo cual visto de improviso, en alguna manera alborotó a don Quijote y puso miedo en el corazón de Sancho; mas luego se alegró don Quijote, creyendo que se le ofrecía alguna nueva y peligrosa aventura, y con este pensamiento, y con ánimo dispuesto de acometer cualquier peligro, se puso delante de la carreta y con voz alta y amenazadora dijo:

-Carretero, cochero o diablo, o lo que eres, no tardes en decirme quién eres, a dó vas y quién es la gente que llevas en tu carricoche, que más parece la barca de Carón que carreta de las que se usan.

A lo cual, mansamente, deteniendo el Diablo la carreta, respondió:

-Señor, nosotros somos recitantes de la compañía de Angulo el Malo. Hemos hecho en un lugar que está detrás de aquella loma, esta mañana, que es la octava del Corpus, el auto de Las Cortes de la Muerte, y hémosle de hacer esta tarde en aquel lugar que desde aquí se parece; y por estar tan cerca y escusar el trabajo de desnudarnos y volvernos a vestir, nos vamos vestidos con los mesmos vestidos que representamos. Aquel mancebo va de Muerte; el otro, de Ángel; aquella mujer, que es la del autor, va de Reina; el otro, de Soldado; aquel, de Emperador, y yo, de Demonio, y soy una de las principales figuras del auto, porque hago en esta compañía los primeros papeles. Si otra cosa vuestra merced desea saber de nosotros, pregúntemelo, que yo le sabré responder con toda puntualidad, que, como soy demonio, todo se me alcanza (Don Quijote, pp. 625-626) ${ }^{39}$.

Y no deja de ser curioso que se invoque ahí, al igual que ocurría en el falso Guzmán con la compañía de Heredia, una empresa teatral auténtica, la de Angulo, una coincidencia que nos lleva a preguntarnos si el falsario era también un escritor dramático aficionado, además de un novelista, como Cervantes mismo. Quevedo, el segundo eslabón de nuestra cadena de imitaciones, se guarda mucho de asociar a su pobre compañía y a sus mediocres actores-escritores con ninguna agrupación histórica.

El primer paso de ese largo camino parece ser el que dio en 1602 un tal Luján de Sayavedra, Mey o quienquiera que escribiese el Guzmán ilegítimo. Ese plagiario valenciano descubrió un nuevo empleo inédito en la picaresca, nunca intuido por Mateo Alemán: el actor-pícaro, colmo

39. En otra parte (2016) he analizado la figura del mal dramaturgo en otras obras cervantinas: en El retablo de las maravillas, en El coloquio de los perros, en la "Adjunta al Parnaso» y en Persiles y Sigismunda. 
del pragmatismo, el arribismo y el fingimiento que definen al arquetipo picaresco. Y en ello le seguirá Quevedo con no poco provecho unos años después, aunque separando el grano de la paja y explotando a su sabor tanto la caricatura metaliteraria como el muestrario del kitsch poético y teatral. Lope de Vega no había llegado a atar cabos ni a troquelar al dramaturgo enajenado, posiblemente porque ese papel le tocaba a la novela, un género descriptivo y, en consecuencia, mucho más propicio para ese tipo de sátira y parodia.

\section{BibLiografía}

Alemán, Mateo, Guzmán de Alfarache, ed. José María Micó, Madrid, Cátedra, 1987.

Alonso Asenjo, José Luis, La Comedia erudita de Sepúlveda: estudio y texto paleográfico-crítico, Londres, Tamesis, 1990.

Arellano, Ignacio, (ed.), Paraninfos, segundones y epígonos de la Comedia del Siglo de Oro, Barcelona, Anthropos, 2004.

Barrio Olano, José Ignacio, «Guzmán de Alfarache y sus secuencias: evolución del personaje», en Actas del xVI Congreso de la Asociación Internacional de Hispanistas: Nuevos caminos del hispanismo, coord. Pierre Civil y Françoise Crémoux, Madrid / Frankfurt am Main, Iberoamericana / Vervuert, 2010, II, p. 54.

Blasco, Javier, ed., Hos ego versiculos feci...: estudios sobre atribución y plagio, Frankfurt am Main, Iberoamericana / Vervuert, 2010.

Brioso Santos, Héctor, «El tópico del mal autor teatral desde el Buscón de Quevedo hasta Moreto, Calderón y Villaviciosa», La transmisión de Quevedo, coords. Flavia Gherardi, Manuel Ángel Candelas Colodrón, Vigo, Academia del Hispanismo, 2015, pp. 153-174.

Brioso Santos, Héctor, «Las tribulaciones del mal poeta dramático, según Cervantes: El retablo de las maravillass, en Vida y escritura en el teatro de Cervantes, ed. Luis Gómez Canseco y María Heredia Mantis, Olmedo, Universidad de Castilla-La Mancha, 2016, pp. 11-32.

Cabo Aseguinolaza, Fernando, “Prólogo», El Buscón, Barcelona, Crítica, 1993, pp. 1-52.

Cascales, Francisco de, Tablas poéticas, ed. Benito Brancaforte, Madrid, Espasa, 1975.

Cavillac, Michel, «La cuestión del «padre» en el Guzmán de Alfarache, desde la 'ética, económica y política'», en Literatura, sociedad y política en el Siglo de Oro. Barcelona-Gerona, 21-24 de octubre de 2009, coords. Eugenia Fosalba Vela y Carlos Vaíllo, Bella Terra, Universitat Autònoma de Barcelona, 2010, pp. 159-173.

Cervantes Saavedra, Miguel de, Don Quïote de la Mancha, ed. Francisco Rico, Madrid, RAE, 2004.

Chevalier, Maxime, «Cuentecillos y chistes tradicionales en la obra de Quevedo», en Cervantesvirtual: http://cvc.cervantes.es/literatura/quevedo_critica/satiras/chevalier.htm

Chevalier, Maxime, Quevedo y su tiempo: la agudeza verbal, Barcelona, Crítica, 1992.

Da Sommaia, Girolamo, Diario de un estudiante de Salamanca, ed. George Haley, Salamanca, Universidad, 1977. 
De Cos Ruiz, Francisco Javier, «Divertimento y enseñanza en los Sueños de Quevedo", Humor y ciencias humanas: actas del I Seminario Interdisciplinar sobre «El Humor y las Ciencias Humanas»: Cádiz, mayo de 2001, Cádiz, Universidad de Cádiz / Servicio de Publicaciones, 2002, pp. 159-172.

Diccionario biográfico de actores del teatro clásico español (DICAT), Kassel, Reichenberger, 2008.

Fernández Nieto, Manuel, Investigaciones sobre Alonso Remón, dramaturgo desconocido del siglo XVII, Madrid, Retorno, 1974.

Francis, Alan, «El Guzmán apócrifo: ¿Picaresca decadente o problemática?», Revista Hispánica Moderna, 39, 1976-1977, pp. 85-95.

García Reidy, Alejandro, «Ocultación y presencia autorial en las fiestas por las dobles bodas reales de 1599 m, en El autor oculto en la literatura española: siglos XIV a XVIII, ed. Maud Le Guellec, Madrid, Casa de Velázquez, 2014, pp. 77-92.

Herrero García, Miguel, «De la profesión a la inadaptación (la sátira social contra los poetas)», Oficios populares en la sociedad de Lope de Vega, Madrid, Castalia, 1977, pp. 231-258.

La Barrera, Cayetano Alberto de, Catálogo bibliográfico y biográfico del antiguo teatro español desde sus orígenes hasta mediados del siglo XVIII, Londres, Tamesis, 1968.

Labourdique, Bernadette, y Michel Cavillac, «Quelques sources du Guzman apocryphe de Mateo Luján», Bulletin Hispanique, 71, 1969, pp. 191-217.

Laguna, Juan I., La Philosophía moral en el Guzmán apócrifo: la autoría de Juan Felipe Mey a la luz de las nuevas fuentes, Ciudad Real, Almud, 2012.

Lázaro Carreter, Fernando, “Originalidad del Buscón», en Francisco de Quevedo, El Buscón, ed. Fernando Cabo Aseguinolaza, Barcelona, Crítica, 1993, pp. IXXXIV.

Mañero Lozano, David, “Introducción», en Segunda parte de la vida del pícaro Guzmán de Alfarache, Madrid, Cátedra, 2007, pp. 11-97.

McGrady, Donald, “Mateo Luján de Sayavedra y López Pinciano», Thesaurus, xxI, 1966, pp. 331-340.

Moreno Mendoza, Arsenio, «La figura del demonio en el teatro y la pintura del Siglo de Oro español», Atrio, 15-16, 2009-2010, pp. 149-156.

Perromat Augustin, Kevin, “Cuervos, cornejas y plumas ajenas. Autoría difusa y reutilización de materiales en el teatro del Siglo de Oro», Lemir, 13, 2009, pp. 261-280.

Profeti, Maria Grazia, y Bernardo García García, (ed.), Lope de Vega, Fiestas de Denia, Florencia, Alinea Editrice, 2004.

Quevedo, Francisco de, El Buscón, ed. Fernando Cabo Aseguinolaza, Barcelona, Crítica, 1993.

Quevedo, Francisco de, Los sueños, ed. Ignacio Arellano, Madrid, Cátedra, 1991.

Rico, Francisco, La novela picaresca y el punto de vista, Barcelona, Seix Barral, 1973.

Rojas Villandrando, Agustín de, El viaje entretenido, ed. Jean-Pierre Ressot, Madrid, Castalia, 1995.

Ruano de la Haza, José María, «Lope and the Theatre in Madrid», en $A$ Companion to Lope de Vega, ed. Alexander Samson y Jonathan Thacker, Londres, Tamesis, 2008, pp. 29-50.

Sánchez Mariana, Manuel, "Los manuscritos dramáticos del Siglo de Oro», en Ex libris. Homenaje al profesor José Fradejas Lebrero, coord. José Nicolás 
Romera Castillo, Ana Freire López y Antonio Lorente Medina, Madrid, UNED, 1993, vol. 1, pp. 441-452.

San Román, Francisco de Borja, Lope de Vega, los cómicos toledanos y el poeta sastre. Serie de documentos inéditos de los años de 1590 a 1615, Madrid, Imprenta Góngora, 1935.

Segunda parte de la vida del pícaro Guzmán de Alfarache, ed. David Mañero Lozano, Madrid, Cátedra, 2007.

Sentaurens, Jean, Séville et le théâtre de la fin du Moyen Âge à la fin de XVII' siècle, Bordeaux, Université de Bordeaux III, 1984.

Sobejano, Gonzalo, “De la intención y valor del Guzmán de Alfarache», Romanische Forschungen, 71, 3-4, 1959, pp. 267-311 (Alicante, Biblioteca Virtual Miguel de Cervantes, 2009, sin paginar).

Sobejano, Gonzalo, «El mal poeta de comedias en la narrativa del siglo XvII», Hispanic Review, 41, 1973, pp. 313-330.

Tropé, Hélène, (ed.), Lope de Vega, Los locos de Valencia, Madrid, Castalia, 2003.

Tobar Quintanar, María José, «El Buscón: una obra juvenil de Quevedo», Archivum, LXI-LXII, 2011-2012, pp. 445-474.

Vega García-Luengos, Germán, «La reescritura permanente del teatro español del Siglo de Oro: nuevas evidencias», en Criticón, "Actas del seminario «Siglo de Oro y reescritura, I: Teatro», 72, 1998 pp. 11-34.

Vitse, Marc, (ed.), "Actas del seminario «Siglo de Oro y reescritura, I: Teatro», Criticón, 72, 1998. 